\section{Thinking of apes}

Intelligence of Apes and Other

Rational Beings

by Duane M. Rumbaugh \&

David A. Washburn

Yale University Press: 2003. 326 pp. \$35

\section{Andrew Whiten}

This intriguing book recounts a lifetime's effort by Duane Rumbaugh to establish an accurate and objective picture of the cognitive capacities of apes and other primates, spanning the past half-century's sea changes in our understanding of animal minds. When Rumbaugh began his career, the field was still dominated by a narrowly focused behaviourism that tended to reduce all learning to simple conditioning. But in the past 20 years, he has collaborated with Sue Savage-Rumbaugh to generate claims of cognitive richness in apes that are about as far from classical behaviourism as it is possible to imagine.

We are treated in this book to an honest and intimate account of Rumbaugh's struggle to square his early training and continuing commitment to behaviourism ("the only data available to our science are behaviors") and to good, objective science (through the use of automated keyboards to record data, for example) with the quirky creativity and rationality that he encountered in decades of work with chimpanzees and other primates.

Examples of this cognitive complexity include both experimental results and oneoff observations of unique, innovative actions. The inherent non-replicability of the latter is of course scientifically problematic, but may nevertheless be the kind of raw material with which any scientific engagement with creative rationality must deal.

An illustration comes from an attempt to use food rewards to train the chimpanzee Lana to urinate in a pan. Rumbaugh points out that, contrary to classical conditioning theory, her response to this reinforcement did not become more vigorous and stronger; instead, she came to eke out her contributions in smaller and smaller doses, thus gaining more rewards. The key observation, however, is that when she had no urine left, she approached the pan and spat into it instead. So what Lana had learned cannot be explained as operant conditioning of her urination behaviour. Her innovation can instead be described as creative, rational and intelligent, and it is one of numerous such cases that pepper the book.

Rumbaugh's half-century scientific quest to understand the kinds of minds that lie behind such episodes may offer an education for the younger generation of researchers who can all too easily fail to appreciate the scope of the intellectual revolution that has taken place. However, Rumbaugh and

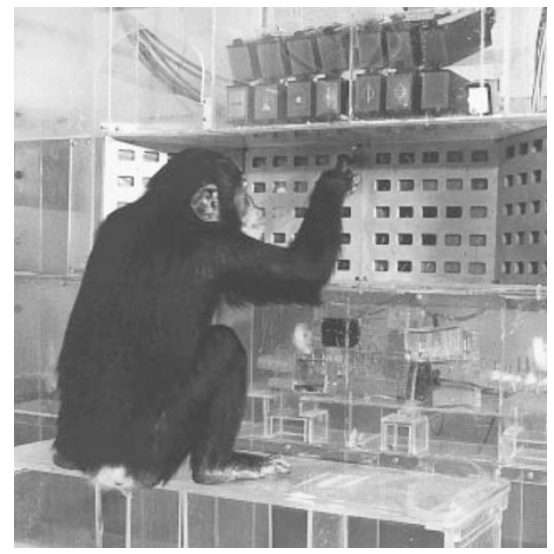

Learning curve: the chimpanzee Lana has taught scientists a great deal about intelligence in apes.

Washburn have greater ambitions: to identify a larger category of complex behaviour, which they call emergents, that goes beyond operants and respondents, integrating all three into a coherent theoretical framework, 'rational behaviourism'. No succinct definition of emergents is offered, but their scope can perhaps be glossed as behaviours for which no specific reinforcement history offers an adequate explanation. These include innovative or creative actions, such as Lana's pan-filling, along with others documented through the quantitative and statistical results of numerous experiments.

Prime examples of these are experiments on 'learning set'. In any series of such experiments, subjects are faced with the same learning contingency, such as that food is hidden under the odd one of three objects, with the objects themselves being changed for each experiment. 'Learning set' refers to the capacity to grasp the overarching rule governing the series (in this case, odd-one-out) such that, over time, successful choices are made faster with each new instantiation of the task. Rumbaugh and Washburn say that this achievement must count as an emergent. Considering this and a range of other kinds of evidence, they conclude that chimpanzees, and probably the other great apes, show the greatest manifestations of emergents, in some cases achieving a qualitative superiority over the smaller-brained monkeys tested.

The book, then, makes two key claims: that our understanding of behaviour is advanced by the concept of emergents, which is in turn nested within rational behaviourism; and that apes show both quantitative and qualitative superiority over other animals in these terms.

Should we buy these claims? On the first, I am sceptical, for several reasons. For a start, it doesn't seem clear that such phenomena as learning sets are inherently more reliant on causal reasoning or other aspects of rationality than simpler kinds of associative learning. Instead, where the latter can be described as learning about first-order patterns in the world (for example, learning that one of three specific objects is the one to pick), the emergent can be described as learning about second-order patterns (that the game is always to pick the odd object among three, say).

My second reason is that contemporary cognitive learning theory seems to have assimilated many of the complexities that the authors worry about, such as the case of Lana learning not a specific behaviour, but about achieving a state of the world (fluid in pan). More bridges have been built between learning theory and the products of the cognitive revolution than the authors acknowledge, so it is a concern that contemporary learning theorists such as Nicholas Mackintosh and Anthony Dickinson, as well as integrators such as Sara Shettleworth, are absent from the bibliography.

I am more convinced of the relative achievements of the apes, as this is consistent with much other evidence. However, Rumbaugh and Washburn fail to cite a recent book - Primate Cognition by Michael Tomasello and Josep Call (Oxford University Press, 1997) - that offers a much more comprehensive overview of the kinds of experiment, such as learning set, that they highlight, but which does not find the overall evidence of qualitative ape superiority persuasive. Such alternative conclusions beg a refutation, if the case for the apes is to be made convincingly.

But perhaps the main strength of Intelligence of Apes and Other Rational Beings is the development of further technologies to probe cognition, most recently the use of computerized joystick-driven tasks. A string of experiments exploiting these advances has already thrown up some fascinating discoveries (ironically, perhaps, mostly in macaque monkeys rather than apes), and I predict that this may represent one of the most influential legacies of the work collated in this volume. Andrew Whiten is at the School of Psychology, University of St Andrews, St Andrews,

Fife KY16 9JU, UK.

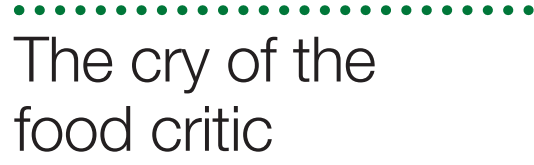

\section{Don't Worry [It's Safe to Eat]. The True Story of GM Food, BSE and Foot and Mouth \\ by Andrew Rowell

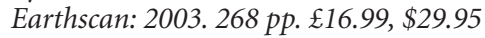

\section{Mark Woolhouse}

Andrew Rowell believes that commercial interests are taking over science, that economic and political pressures are brought to bear on researchers, and that those with unorthodox views are subject to intimidation and vilification. He makes these serious 
charges in his topical, well-publicized and widely discussed volume Don't Worry [It's Safe to Eat].

The scientific and political histories of genetically modified (GM) foods provide many of the illustrations of the book's main themes, although Rowell claims that the book is not anti-GM. He also uses mad-cow disease (bovine spongiform encephalopathy, or BSE) and foot-and-mouth disease to back up his claim that critical voices are marginalized in scientific debates. He considers that, in these areas, the British public has been "betrayed" by the scientific establishment. Few escape his reprobation: the UK government, industry, the universities, the Department for Environment, Food and Rural Affairs, the Food Standards Agency, the Biotechnology and Biological Sciences Research Council (Britain's main funding agency for research in non-medical life sciences) and the Royal Society all fare badly. Nature is also censured, for its "fudged" retraction of a publication on GM maize.

It is easy to agree with many of the general points that Rowell makes. Scientific advice to industry or government should reflect genuine scientific uncertainties. Absence of evidence is not evidence of absence; where more research is warranted into possible public health risks or the like, it should be carried out. Research results, properly arrived at, should not be suppressed, however inconvenient they may be. Scientific controversies should be resolved by open debate, free of intimidation and harassment. If, as Rowell believes, these self-evident rules are repeatedly being broken, then that would indeed be a cause for concern.

It is the specifics that let the book down. No one could dispute that there have been heated controversies over GM food, BSE and foot-and-mouth disease, but the accounts given here are so one-sided as to put off anyone other than the most hardened conspiracy theorist. Rowell, an investigative journalist, uses a wide variety of sources ranging from Nature through reports of government inquiries to the satirical magazine Private Eye, supplemented by numerous interviews - but he uses them selectively, sometimes perpetuating misconceptions (for example, about how models of foot-andmouth disease were developed) in making his case. There are significant omissions too. For example, Rowell develops at length the theme that there was a collective unwillingness to determine whether BSE posed a public-health risk, without mentioning that the CJD Surveillance Unit was set up in Edinburgh in 1990 in response to the Southwood Report for just that reason.

Rowell is also unwilling to consider that unexpected (and sometimes unwelcome) findings might be criticized for no more sinister reason than that the underlying methodology is flawed. The objective of peer

\section{Exhibition}

\section{A hobbit-forming show}

This cave-troll stars in an exhibition at the Science

Museum in London to celebrate the technology used to make the hugely successful films based on J. R. R. Tolkien's novel The Lord of the Rings.

Some film-makers would have shot the epic trilogy entirely in the computer, but director Peter Jackson used techniques ranging from advanced mathematical modelling and virtual reality to Medieval methods of armour manufacture.

Some have commented that it is hardly the business of a science museum to give space to a show about a fantasy film. In response, the museum's exhibition manager, James Rudoni, says that the exhibition is "quite simply about the science and technology behind the most incredible movie project ever undertaken. The exhibition looks behind the innovation of the film-makers."

Some 18,000 visitors went to see the exhibition in its first week alone. It runs until

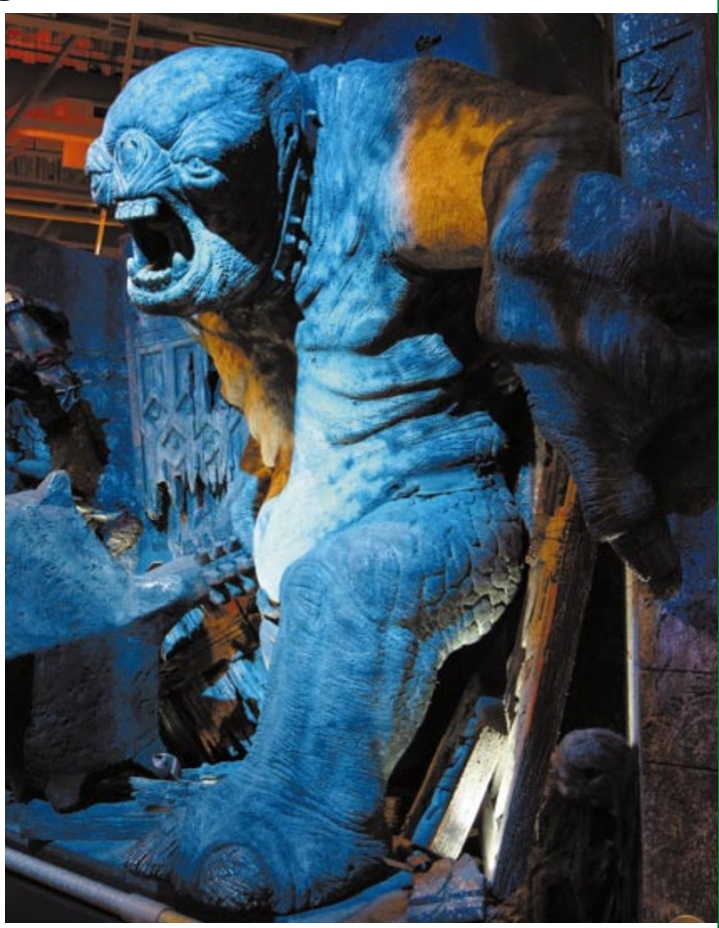

11 January 2004 before moving to Singapore, Boston and Sydney.

http://www.sciencemuseum.org.uk/ exhibitions/lordoftherings/default_flash.asp review is not, as he seems to imply, to preserve the status quo for its own sake, but to filter out bad science. It is often true that controversial and high-profile results receive much closer scrutiny than routine results; that is hardly surprising. What matters is that such scrutiny takes place, is fair and works to generally accepted standards. In fact, much of the 'science' reported in this book appears not to have been subject to peer review at all.

Nevertheless, the book does raise the important question of how science should relate to industry and government while retaining its independence and working, as a publicly funded enterprise should, for the public good and with the public's trust. Rowell offers several suggestions in his final chapter, based on the three fine-sounding "principles" of humility, pluralism and diversity. Personally, I was too disenchanted by what had gone before to be overly impressed by these offerings; other readers may be more patient and charitable.

As this book illustrates, how science and scientists are perceived is changing in an important way. Nowadays, the pronouncements of the scientific establishment are not going to be accepted just because it is the scientific establishment. Alternative views will be sought and, if only because scientists are always ready (thankfully) to challenge main- stream thinking, they will often be found. This is all to the good: debate is vital, and should be warmly welcomed. The point to emphasize is that it must be informed and responsible debate.

This is especially important when scientific disagreements have a direct effect on the public. For example, the recent controversy in Britain about an alleged association between the MMR vaccine (for mumps, measles and rubella) and autism is widely held to be responsible for a recent fall in vaccination coverage. This in turn has potentially serious public-health consequences of its own - a point that Rowell fails to make in a passing reference to this topic.

Ultimately, it is up to the scientists themselves to ensure that the debate is both informed and responsible. The artist James McNeill Whistler put it well in 1878: "I maintain that two and two would continue to make four, in spite of the whine of the amateur for three, or the cry of the critic for five." GM food, BSE and foot-and-mouth disease have all produced a great deal of crying and whining, but this must not goad scientists working on these subjects into making their two and two into anything other than four. Mark Woolhouse is at the Centre for Infectious Diseases, University of Edinburgh, Easter Bush, Midlothian EH25 9RG, UK. 